\title{
Karakteristik Pasien Gagal Jantung Akut di RSUP Prof Dr. R. D. Kandou Periode Januari-Desember 2018
}

\author{
Rudolof A. Donsu, ${ }^{1}$ Starry H. Rampengan, ${ }^{2}$ Natalia Polii ${ }^{2}$
}

\author{
${ }^{1}$ Program Studi Pendidikan Dokter Fakultas Kedokteran Universitas Sam Ratulangi Manado \\ ${ }^{2}$ Bagian Kardiologi dan Kedokteran Vaskular Fakultas Kedokteran Universitas Sam \\ Ratulangi Manado \\ Email: Folod25@gmail.com
}

\begin{abstract}
Acute heart failure itself is a life-threatening medical condition that needs urgent medical attention. The cases of acute heart failure are expected to rise in the future due to the increase in life expectancy and advancement of therapy of myocardial infarct that causes the improvement of life expectancy among patients with decreased cardiac function. This study was aimed to obtain the characteristics of acute heart failure patients at Prof. Dr. R. D. Kandou from January to December 2018. The results showed a total of 130 patients that had acute heart failure in 2018, however, only 89 patients fulfilled the inclusion criteria consisting of 52 males $(58 \%)$ and 37 females (42\%). The highest percentages among the patients' characteristics were, as follows: age >60 years (55\%), hypertension as the etiology (37\%), hemodynamic profile was wet-warm $(56.2 \%)$, ejection fraction $<40 \%$ on echocardiography (41.6\%), atrial tachycardia/flutter/fibrillation on ECG (39.1\%), CTR $>50 \%$ on X-ray images $(98 \%)$, and diuretics usage inpatients and outpatients $(89 \%$ and $82 \%)$. In conclusion, the majority of patients with acute heart failure in 2018 were male, age $>60$ years, had hypertension as the etiology, wet-warm hemodynamic profile, ejection fraction on echocardiogram $<40 \%$, atrial tachycardia/flutter/fibrillation on ECG, CTR $>50 \%$ on X-ray images, and diuretics usage.
\end{abstract}

Keywords: acute heart failure, characteristics of patients

\begin{abstract}
Abstrak: Gagal jantung akut merupakan suatu kondisi medis yang mengancam jiwa dan membutuhkan penanganan yang cepat dan tepat. Kejadian gagal jantung diperkirakan akan semakin meningkat di masa depan, karena semakin bertambahnya usia harapan hidup dan berkembangnya terapi penanganan infark miokard yang mengakibatkan perbaikan harapan hidup penderita dengan penurunan fungsi jantung. Penelitian ini bertujuan untuk mendapatkan karakteristik pasien gagal jantung akut di RSUP Prof. Dr. R. D. Kandou periode JanuariDesember 2018. Hasil penelitian mendapatkan total pasien gagal jantung akut sebanyak 130 orang dan yang memenuhi kriteria inklusi sebanyak 89 orang, terdiri dari 52 orang (58\%) lakilaki dan 37 orang $(42 \%)$ perempuan. Persentase tertinggi pada karakteristik pasien ialah usia $>60$ tahun (55\%), etiologi hipertensi (37\%), profil hemodinamik wet-warm $(56,2 \%)$, fraksi ejeksi pada ekokardiogram $<40 \%$ (41,6\%), gambaran EKG atrial takikardia/flutter/fibrilasi $(39,1 \%)$, CTR $>50 \%$ pada foto polos dada (98\%), dan penggunaan obat diuretik baik selama perawatan dan saat keluar rumah sakit (89\% dan 82\%). Simpulan penelitian ini ialah mayoritas pasien gagal jantung akut pada tahun 2018 berjenis kelamin laki-laki, usia $>60$ tahun, etiologi hipertensi, profil hemodinamik wet-warm, fraksi ejeksi pada ekokardiogram $<40 \%$, gambaran EKG atrial takikardia/ flutter/fibrilasi, CTR $>50 \%$ pada foto polos dada, dan penggunaan obat diuretik.
\end{abstract}

Kata kunci: gagal jantung akut, karakteristik pasien 


\section{PENDAHULUAN}

Gagal jantung akut adalah serangan akut dari gejala gagal jantung akibat kelainan struktur dan fungsi jantung, dapat didahului ataupun tanpa sakit jantung sebelumnya. Kelainan struktur dan fungsi jantung dapat berupa disfungsi sistolik dan disfungsi diastolik, irama jantung yang tidak abnormal, dan pre-load dan afterload yang tidak seimbang. Kejadian ini harus dianggap serius untuk segera dilakukannya penyelamatan jiwa dan pengobatan pasien secara cepat dan tepat. ${ }^{1}$ Menurut American Heart Association di Amerika Serikat, sekitar 5 juta orang dewasa setiap tahun sekitar 550.000 pasien didiagnosis. Gagal jantung bertanggung jawab atas sekitar 287.000 kematian per tahun. $^{2}$

Menurut data Riskesdas 2013, di Indonesia prevalensi penyakit gagal jantung berdasarkan diagnosis dokter yang sudah ditegakkan diperkirakan $0,13 \%$ atau 229,696 orang, dan berdasarkan diagnosis kerja atau gejala $0,3 \%$ atau sekitar 530.068 orang. Berdasarkan diagnosis dokter, estimasi jumlah penderita penyakit gagal jantung terbanyak terdapat di Provinsi Jawa Timur sebanyak 54.826 orang $(0,19 \%)$, sedangkan di Provinsi Maluku Utara terdapat jumlah penderita paling sedikit, yaitu sebanyak 144 orang $(0,02 \%){ }^{3}$ Penelitian yang dilakukan di Bagian Kardiologi RSUP Prof. Dr. R. D Kandou Manado sejak bulan September-November 2016 mendapatkan 78 pasien gagal jantung akut, terdiri dari 44 pasien laki-laki dan 34 pasien perempuan. ${ }^{4}$

Berdasarkan latar belakang ini, penulis tertarik untuk meneliti karakteristik pasien gagal jantung akut di RSUP Prof. Dr. R. D. Kandou, dengan periode pengamatan yang lebih panjang yaitu Januari s/d Desember 2018. Karakteristik tersebut antara lain: profil hemodinamik, gambaran rontgen, dan elektrokardiogram yang diharapkan akan memberikan tambahan informasi untuk melengkapi penelitian ini.

\section{METODE PENELITIAN}

Penelitian ini dilakukan pada bulan September-November 2019. Jenis penelitian ini ialah deskriptif observasional dengan desain potong lintang menggunakan data rekam medik pasien. Populasi penelitian ini ialah seluruh pasien gagal jantung di RSUP Prof. Dr. R. D. Kandou periode Januari-Desember 2018 sedangkan sampel penelitian ini ialah seluruh pasien gagal jantung akut di RSUP Prof. Dr. R. D. Kandou periode Januari-Desember 2018 yang memenuhi kriteria inklusi. Pasien yang memenuhi kriteria inklusi bila diagnosis yang ditegakkan ialah gagal jantung akut dengan rekam medik lengkap yaitu data pemeriksaan ekokardiografi, elektrokardiogram, dan rontgen. Pasien dengan data rekam medik tidak lengkap dieksklusikan dari penelitian ini. Variabel penelitian ini ialah usia, jenis kelamin, etiologi, faktor pencetus, parameter fraksi ejeksi (ekokardiografi), rontgen, elektrokardiogram, dan obat-obatan.

Penelitian ini telah mendapat persetujuan dari Komisi Etik Penelitian Kesehatan RSUP Prof. Dr. R. D. Kandou Manado, dengan nomor keterangan layak etik yaitu No. 063/EC/KEPK-KANDOU/X/2019.

\section{HASIL PENELITIAN}

Hasil penelitian ini mendapatkan total pasien gagal jantung akut sebanyak 130 orang dan yang memenuhi kriteria inklusi sebanyak 89 orang, terdiri dari 52 orang (58\%) laki-laki dan 37 orang (42\%) perempuan.

Tabel 1 memperlihatkan distribusi pasien gagal jantung akut berdasarkan usia. Pasien terbanyak berada pada kelompok usia >60 tahun yaitu 49 orang (55\%), disusul kelompok usia 50-59 tahun yaitu 20 orang (22,4\%), kelompok usia 40-49 tahun yaitu 17 orang $(19,1 \%)$, dan yang paling sedikit ialah kelompok usia $<40$ tahun yaitu 3 orang $(3,3 \%)$.

Tabel 1. Distribusi pasien gagal jantung akut berdasarkan kelompok usia

\begin{tabular}{ccc}
\hline $\begin{array}{c}\text { Usia } \\
\text { (tahun) }\end{array}$ & $\begin{array}{c}\text { Jumlah } \\
(\mathbf{n = 8 9})\end{array}$ & Persentase \\
\hline$<40$ & 3 & $3,4 \%$ \\
$40-49$ & 17 & $19,1 \%$ \\
$50-59$ & 20 & $22,5 \%$ \\
$>60$ & 49 & $55 \%$ \\
\hline
\end{tabular}


Tabel 2 memperlihatkan distribusi pasien gagal jantung akut berdasarkan etiologi. Pasien dengan etiologi terbanyak ialah hipertensi sebanyak 33 orang (37\%), penyakit jantung koroner sebanyak 24 orang $(26 \%)$, aritmia sebanyak 17 orang (20\%), kelainan katup jantung sebanyak 14 orang (16\%), dan penyakit jantung bawaan sebanyak 1 orang $(1 \%)$.

Tabel 2. Distribusi pasien gagal jantung akut berdasarkan etiologi

\begin{tabular}{lcc}
\hline \multicolumn{1}{c}{ Etiologi } & $\begin{array}{c}\text { Jumlah } \\
(\mathbf{n = 8 9 )}\end{array}$ & Persentase \\
\hline $\begin{array}{l}\text { Hipertensi } \\
\text { Kelainan }\end{array}$ & 33 & $37 \%$ \\
katup jantung & 14 & $16 \%$ \\
$\begin{array}{l}\text { Penyakit } \\
\text { jantung koroner }\end{array}$ & 24 & $26 \%$ \\
$\begin{array}{l}\text { Penyakit } \\
\text { jantung bawaan }\end{array}$ & 1 & $1 \%$ \\
Aritmia & 17 & $20 \%$ \\
\hline
\end{tabular}

Tabel 3 memperlihatkan distribusi pasien gagal jantung akut berdasarkan profil hemodinamik. Yang terbanyak ialah wetwarm pada 50 pasien $(56,2 \%)$, dry-cold pada 27 pasien $(30,4 \%)$, wet-warm pada 6 pasien $(6,7 \%)$, dan wet-cold pada 6 pasien $(6,7 \%)$.

Tabel 4 memperlihatkan distribusi pasien gagal jantung akut berdasarkan fraksi ejeksi. Didapatkan fraksi ejeksi 50\%$70 \%$ pada 35 pasien $(39,3 \%), 40 \%-49 \%$ pada 17 pasien $(19,1 \%)$, dan $<40 \%$ pada 37 pasien $(41,6 \%)$.
Tabel 3. Distribusi pasin gagal jantung akut berdasarkan profil hemodinamik

\begin{tabular}{ccc}
\hline $\begin{array}{c}\text { Profil } \\
\text { hemodinamik }\end{array}$ & $\begin{array}{c}\text { Jumlah } \\
(\mathbf{n = 8 9})\end{array}$ & Persentase \\
\hline Dry - Cold & 27 & $30,4 \%$ \\
Wet - Cold & 6 & $6,7 \%$ \\
Wet - Warm & 50 & $56,2 \%$ \\
Dry - Warm & 6 & $6,7 \%$ \\
\hline
\end{tabular}

Tabel 4. Distribusi pasien gagal jantung akut berdasarkan fraksi ejeksi

\begin{tabular}{ccc}
\hline $\begin{array}{c}\text { Fraksi } \\
\text { ejeksi }\end{array}$ & $\begin{array}{c}\text { Jumlah } \\
(\mathbf{n}=\mathbf{8 9})\end{array}$ & Persentase \\
\hline $50-70 \%$ & 35 & $39,3 \%$ \\
$40-49 \%$ & 17 & $19,1 \%$ \\
$<40 \%$ & 37 & $41,6 \%$ \\
\hline
\end{tabular}

Tabel 5 memperlihatkan distribusi pasien gagal jantung akut berdasarkan pemeriksaan electrokardiogram (EKG). Didapatkan atrial takikardi/flutter/fibrilasi pada 35 pasien $(39,1 \%)$, iskemia pada 7 pasien $(8,2 \%)$, infark pada 3 pasien $(4,1 \%)$, durasi QRS >0,12 detik pada 12 pasien $(13,1 \%)$, gelombang $\mathrm{Q}$ pada 10 pasien $(11,1 \%)$, hipertrofi ventrikel kiri pada 7 pasien $(8,2 \%)$, lain-lain yang terdiri dari sinus takikardi, sinus bradikardi, dan normal sinus rythm pada 15 pasien $(16,2 \%)$.

Tabel 6 memperlihatkan distribusi pasien gagal jantung akut berdasarkan pemeriksaan foto polos dada. Didapatkan hasil CTR $<50 \%$ pada 2 pasien $(2 \%)$, dan CTR $>50 \%$ pada 87 pasien $(98 \%)$.

Tabel 5. Distribusi pasien gagal jantung akut berdasarkan EKG

\begin{tabular}{ccc}
\hline EKG & $\begin{array}{c}\text { Jumlah } \\
(\mathbf{n = 8 9})\end{array}$ & Persentase \\
\hline Atrial takikardia/ flutter/fibrilasi & 35 & $39,1 \%$ \\
Iskemia & 7 & $8,2 \%$ \\
Infark & 3 & $4,1 \%$ \\
Gelombang Q & 10 & $11,1 \%$ \\
Hipertrofi ventrikel kiri & 7 & $8,2 \%$ \\
Durasi QRS > 0,12 detik & 12 & $13,1 \%$ \\
Lain-lain & 15 & $16,2 \%$ \\
\hline
\end{tabular}


Tabel 6. Distribusi pasien gagal jantung akut berdasarkan cardio thoracic ratio (CTR)

\begin{tabular}{ccc}
\hline CTR & $\begin{array}{c}\text { Jumlah } \\
(\mathbf{n = 8 9})\end{array}$ & Persentase \\
\hline$<50 \%$ & 2 & $2 \%$ \\
$>50 \%$ & 87 & $98 \%$ \\
\hline
\end{tabular}

Tabel 7 memperlihatkan distribusi pasien gagal jantung akut berdasarkan faktor pencetus. Didapatkan hipertensi tidak terkontrol pada 40 pasien $(45 \%)$, iskemia akut/infark pada 35 pasien (39\%), tidak patuh komsumsi obat pada 10 pasien $(12 \%)$, dan endokarditis pada 4 pasien $(4 \%)$.

Tabel 8 memperlihatkan distribusi pasien gagal jantung akut berdasarkan obat di rumah sakit. Obat yang didapatkan ialah diuretik pada 79 pasien (89\%), ACEinhibitors pada 41 pasien $(46 \%)$, penyekat $\beta$ pada 39 pasien (44\%), antagonis aldosteron pada 27 pasien $(30,3 \%)$, ARB pada 15 pasien $(17 \%)$, dan nitrat pada 32 pasien $(36 \%)$.

Tabel 9 memperlihatkan distribusi pasien gagal jantung akut berdasarkan obat pulang keluar rumah sakit. Obat yang didapatkan ialah diuretik pada 73 pasien (82\%), ACE-inhibitors pada 48 pasien (54\%), penyekat $\beta$ pada 40 pasien $(45 \%)$, antagonis aldosteron pada 16 pasien (18\%), ARB pada 17 pasien (19\%), dan nitrat pada 36 pasien $(40,4 \%)$

Tabel 7. Distribusi pasien gagal jantung akut berdasarkan faktor pencetus

\begin{tabular}{lcc}
\hline \multicolumn{1}{c}{ Faktor pencetus } & $\begin{array}{c}\text { Jumlah } \\
(\mathbf{n = 8 9 )}\end{array}$ & Persentase \\
\hline Tidak patuh konsumsi obat & 10 & $12 \%$ \\
Iskemia akut atau infark & 35 & $39 \%$ \\
Hipertensi tidak terkontrol & 40 & $45 \%$ \\
Endokarditis & 4 & $4 \%$ \\
\hline
\end{tabular}

Tabel 8. Distribusi pasien gagal jantung akut berdasarkan obat di rumah sakit

\begin{tabular}{lcc}
\hline \multicolumn{1}{c}{ Obat di RS } & $\begin{array}{c}\text { Jumlah } \\
(\mathbf{n = 8 9})\end{array}$ & Persentase \\
\hline Diuretik & 79 & $89 \%$ \\
Ace-inhibitors & 41 & $46 \%$ \\
Penyekat $\beta$ & 39 & $44 \%$ \\
Antagonis aldosteron & 27 & $30,3 \%$ \\
ARB & 15 & $17 \%$ \\
Nitrat & 32 & $36 \%$ \\
\hline
\end{tabular}

*Jumlah pasien di atas lebih dari 89 dikarenakan setiap pasien memiliki lebih dari satu pemberian obat di rumah sakit

Tabel 9. Distribusi pasien gagal jantung akut berdasarkan obat pulang keluar rumah Sakit

\begin{tabular}{ccc}
\hline $\begin{array}{c}\text { Obat pulang keluar } \\
\text { rumah sakit }\end{array}$ & $\begin{array}{c}\text { Jumlah } \\
(\mathbf{n = 8 9})\end{array}$ & Persentase \\
\hline Diuretik & 73 & $82 \%$ \\
ACE-inhibitors & 48 & $54 \%$ \\
Penyekat $\beta$ & 40 & $45 \%$ \\
Antagonis aldosteron & 16 & $18 \%$ \\
ARB & 17 & $19 \%$ \\
Nitrat & 36 & $40,4 \%$ \\
\hline
\end{tabular}

*Jumlah pasien di atas lebih dari 89 dikarenakan setiap pasien memiliki lebih dari satu pemberian 


\section{BAHASAN}

Penelitian pada pasien gagal jantung akut di RSUP Prof. Dr. R. D. Kandou periode Januari-Desember 2018 mendapatkan 89 pasien yag memenuhi kriteria inklusi. Berdasarkan jenis kelamin, yang terbanyak ialah jenis kelamin laki-laki sebanyak 52 pasien (58\%) dibandingkan dengan perempuan sebanyak 37 pasien $(42 \%)$. Eugenio et $\mathrm{al}^{5}$ menyatakan di sembilan negara di Asia salah satunya Indonesia, masing-masing melaporkan pasien laki-laki $(66 \%)$ lebih banyak daripada perempuan $(34 \%)$. Laki-laki cenderung memiliki pola hidup tidak sehat berupa kebiasaan merokok dan mengonsumsi minuman beralkohol yang berlebih sehingga meningkatkan risiko terhadap berbagai penyakit dibandingkan perempuan. ${ }^{6}$ Selain itu, perempuan mempunyai hormon estrogen yang memiliki efek perlindungan pada sistem kardiovaskular. Situasi ini membuat perempuan yang menderita penyakit jantung koroner lebih lambat menunjukkan efeknya, yaitu sekitar 10 tahun lebih lambat dari pada laki-laki. ${ }^{7}$

Pada distribusi jumlah pasien berdasarkan kelompok usia didapatkan 49 pasien berusia $>60$ tahun $(55 \%)$, diikuti 20 pasien berusia 50-59 tahun (22,5\%), dan 17 pasien berusia 40-49 tahun $(19,1 \%)$. Pablo dan Fernando ${ }^{8}$ menyatakan bahwa pasien gagal jantung akut paling umum untuk perawatan di rumah sakit berusia $>60$ Tahun. Dengan bertambahnya usia, terjadi penurunan baik dalam jumlah dan fungsi miosit jantung, peningkatan nekrosis dan apoptosis miosit, serta penurunan kapasitas regeneratif selsel progenitor jantung. ${ }^{9}$ Keadaan ini memengaruhi seluruh sistem pembuluh darah dan menyebabkan fibrosis dinding pembuluh darah arteri serta penebalan, dan pengerasan dinding pembuluh darah sehingga semakin menambah tekanan jantung dan memperburuk hipertrofi. Mekanisme ini dapat berujung pada berkembangnya penyakit gagal jantung. ${ }^{9}$

Pada distribusi jumlah pasien berdasarkan profil hemodinamik yang terbanyak ialah wet-warm pada 50 pasien $(56,2 \%)$, dry-cold pada 27 pasien $(30,4 \%)$, wet-warm pada 6 pasien $(6,7 \%)$, dan wet-cold pada 6 pasien (6,7\%). The ESC-EORP HFA Heart Failure Long-Term Registry menyatakan dari 7865 pasien gagal jantung akut pada saat masuk rumah sakit ditemukan $69,9 \%$ dengan gambaran wet-warm. ${ }^{10}$ European Society of Cardiology 2016, menyatakan 95\% pasien dengan gagal jantung akut di rumah sakit memiliki gambaran klinis kongesti (wet). Biasanya pasien datang dalam keadaan yang lebih berat dengan gambaran klinis utama yaitu kongesti dan dipersulit oleh beberapa faktor komorbiditas medis lainnya. ${ }^{11}$

Distribusi jumlah pasien berdasarkan etiologi ialah hipertensi pada 33 pasien (37\%), penyakit jantung koroner 24 pasien (26\%), aritmia 17 pasien (20\%), kelainan katup jantung 14 pasien (16\%), dan penyakit jantung bawaan 1 pasien (1\%). Bharathi et $\mathrm{al}^{12}$ menyatakan hipertensi merupakan faktor risiko paling umum yaitu 70\%-80\% untuk pasien gagal jantung. Hipertensi dapat menyebabkan kerusakan serius pada jantung. Tekanan yang berlebihan membuat pembuluh darah menjadi sklerosis serta aliran darah dan oksigen ke jantung berkurang. ${ }^{13}$ Tekanan darah yang meningkat dan aliran darah yang berkurang ini dapat menyebabkan gagal jantung dan jantung tidak dapat memompa cukup darah dan oksigen ke organ tubuh vital lainnya. ${ }^{13}$ Pola hidup pada masyarakat ditandai dengan adanya gaya hidup yang tidak sehat, menyebabkan hipertensi menempati urutan pertama dalam penyakit tidak menular tahun 2017 dengan jumlah 14.961 kasus di Kota Manado. ${ }^{14}$

Pada distribusi berdasarkan faktor pencetus didapatkan yang terbanyak ialah hipertensi tidak terkontrol 40 pasien $(45 \%)$, iskemia akut/infark 35 pasien (39\%), endokarditis 4 pasien (4\%), dan tidak patuh komsumsi obat 10 pasien (12\%). Devina et $\mathrm{al}^{4}$ melaporkan bahwa di rawat inap RSUP Prof Dr. R. D. Kandou tahun 2016 terdapat $41 \%$ pasien gagal jantung akut disebabkan hipertensi tidak terkontrol. Diperkirakan lebih dari $50 \%$ pasien hipertensi tidak patuh terhadap obat/rejimen yang ditentukan sebelumnya. ${ }^{15}$ 
Distribusi pasien gagal jantung akut berdasarkan fraksi ejeksi ialah 50-70\% pada 35 pasien $(39,3 \%), 40-49 \%$ pada 17 pasien $(19,1 \%)$, dan $<40 \%$ pada 37 pasien (41,6\%). Brigham and Women's Hospital dengan pemeriksaan ekokardiografi melaporkan bahwa dari 908 pasien didapatkan 620 pasien dengan fraksi ejeksi $<40 \% .^{16}$ Pengukuran fraksi ejeksi $<40 \%$ dapat merupakan bukti adanya gagal jantung. ${ }^{17}$ Gagal jantung dapat terjadi karena penurunan progresif fungsi kontraktil miokard (disfungsi sistolik) yang mengakibatkan penurunan fraksi ejeksi dari nilai normal. Pengurangan fraksi ejeksi dapat terjadi karena cedera iskemik, adaptasi yang tidak memadai terhadap tekanan atau volume berlebih karena hipertensi atau penyakit katup, atau pelebaran ventrikel. Gagal jantung diakui sebagai hasil dari ketidakmampuan bilik jantung untuk mengembang dan mengisi secara cukup selama disfungsi diastolik, misalnya, akibat hipertrofi ventrikel kiri, fibrosis miokard, perikarditis konstriktif, atau deposisi amiloid. ${ }^{18}$

Distribusi pasien gagal jantung akut berdasarkan gambaran elektrokardiogram (EKG) mendapatkan atrial takikardi/flutter/ fibrilasi pad 35 pasien $(39,1 \%)$, iskemia 7 pasien $(8,2 \%)$, infark 3 pasien $(4,1 \%)$, durasi QRS $>0,12$ detik 12 pasien $(13,1 \%)$, gelombang Q 10 pasien $(11,1 \%)$, hipertrofi ventrikel kiri 7 pasien $(8,2 \%)$, dan lain-lain yang terdiri dari sinus takikardi, sinus bradikardi, dan normal sinus rhythm yaitu 15 pasien (16.2\%). Farhan dan Gregory mendapatkan $>50 \%$ pasien dengan atrial fibrilasi permanen memiliki diagnosis bersamaan gagal jantung; hal ini menyebabkan bertambahnya jumlah pasien rawat inap yang lebih lama dan peningkatan mortalitas pada pasien gagal jantung dengan atrial fibrilasi. ${ }^{19}$ Ketidakseimbangan neurohormonal dan aktivitas renin-angiotensinaldosteron system (RAAS) menyebabkan perubahan fisiologis maladaptif termasuk peningkatan preload dan afterload; hal ini dapat menyebabkan peningkatan peregangan atrium kiri dan terjadi fibrosis yang mencetuskan gangguan konduksi dan menyebabkan atrial fibrilasi. ${ }^{20}$
Distribusi pasien gagal jantung akut berdasarkan pemeriksaan rontgen ialah CTR $<50 \%$ pada 2 orang ( $2 \%$ ), dan $>50 \%$ pada 87 orang $(98 \%)$. Leticia et $\mathrm{al}^{21}$ menyatakan bahwa kardiomegali dikaitkan dengan gagal jantung sebesar 70,8\%. Diameter jantung lebih atau sama dengan $50 \%$ adalah kardiomegali atau pembesaran jantung. ${ }^{22}$ Pemeriksaan ini merupakan tes yang membantu diagnosis gagal jantung. ${ }^{23}$ Peningkatan berkelanjutan kerja jantung karena tekanan atau volume berlebih misalnya hipertensi sistemik atau stenosis aorta menyebabkan miosit jantung mengalami hipertrofi secara kumulatif, yang meningkatkan ukuran dan berat jantung. ${ }^{24}$

Distribusi pasien gagal jantung akut menurut obat-obatan yang dikonsumsi di rumah sakit ialah diuretik 79 pasien (89\%), ACE-inhibitors 41 pasien (46\%), penyekat $\beta 39$ pasien (44\%), antagonis aldosteron 27 pasien $(30 \%)$, ARB 15 pasien $(17 \%)$, dan nitrat 32 pasien (36\%). Alberto et $\mathrm{al}^{25}$ menyatakan bahwa $90 \%$ kasus pasien gagal jantung di rumah sakit menggunakan diuretik sebagai pendekatan terapi awal. Diuretik terutama loop diuretics yaitu furosemide, torsemide, bumetanide dengan pendekatan dosis awal merupakan obat yang berefek menghilangkan gejala dan peningkatan kelebihan cairan, termasuk gagal jantung akut. Loop diuretics dapat menyebabkan ekskresi hingga 25\% dari natrium yang difiltrasi dan dengan pemberian intra vena memungkinkan onset yang cepat, biasanya dalam 30 hingga 60 menit. Diuretik memiliki efek dilatasi vena yang cepat yang dapat menurunkan tekanan pengisian ventrikel kiri dan segera meringankan gejala kongesti paru sebelum diuresis terjadi. ${ }^{26}$

Obat-obatan yang dikonsumsi setelah pasien keluar rumah sakit ialah diuretik pada 73 pasien (82\%), ACE-inhibitors pada 48 pasien (54\%), penyekat $\beta$ pada 40 pasien (45\%), antagonis aldosteron pada 16 pasien (18\%), ARB pada 17 pasien (19\%), dan nitrat pada 36 pasien (40\%). Ryder et $\mathrm{al}^{27}$ menyatakan pada pasien gagal jantung akut yang diberikan pengobatan diuretik pasca perawatan di rumah sakit didapatkan 
bahwa $72 \%$ pasien tersebut memiliki gagal jantung akut stabil dan tidak terjadi kekambuhan atau bahkan mengalami kematian.

\section{SIMPULAN}

Pada kasus gagal jantung akut di RSUP Prof. Dr. R. D. Kandou periode Januari s/d Desember 2018 didapatkan bahwa pasien yang terbanyak ialah berjenis kelamin laki-laki, usia >60 tahun, etiologi hipertensi, profil hemodinamik wet-warm, fraksi ejeksi pada ekokardiogram $<40 \%$, gambaran EKG atrial takikardia/flutterl fibrilasi, CTR $>50 \%$ pada foto polos dada, dan penggunaan obat diuretik.

Bagi peneliti lanjut disarankan untuk menambahkan variabel lain seperti pemeriksaan laboratorium dan data pasien saat keluar rumah sakit (pulang hidup dan pulang meninggal), serta menggunakan metode penelitian analitik.

\section{Konflik Kepentingan}

Penulis menyatakan tidak terdapat konflik kepentingan dalam studi ini.

\section{DAFTAR PUSTAKA}

1. Aru WS, Bambang S, Irdus A, Marchellus SK, Siti S. Buku Ajar Ilmu Penyakit Dalam Jilid III (4th ed). Jakarta: Departemen Ilmu Penaykit Dalam Fakultas Kedokteran Universitas Indonesia, 2006; p. 1513-4.

2. Wanda MP, Adnan M, Heart failure and cardiomyopathies. Roberta Hines. Stoelting's Anasthesia and Co-existing Disease (7th ed). New Haven, Elsevier, 2018; p. 199-223

3. Pusat Data dan Informasi Kementerian Kesehatan RI 2014. Situasi Kesehatan Jantung. 2014. Jakarta: Kementerian Kesehatan Republik Indonesia; p.1-8.

4. Haris DE, Rampengan SH, Jim EL, Gambaran pasien gagal jantung akut yang menjalani rawat inap di RSUP Prof Dr. R. D. Kandou Periode SeptemberNovember 2016. E-CliniC. 2016;4(2).

5. Reyes EB, Ha JW, Firdaus I, Ghazi AM, Phrommintikul A, Sim D, et al. Heart failure across Asia: same healthcare burden but differences in organization of care. International Journal of Cardiology. 2016;223:163-7.
6. Wannamethee SG, Whincup PH, Lennon L, Papacosta O, Shaper AG. Alcohol consumption and risk of incident heart failure in older men: a prospective cohort study. British Medical Journal. 2015;2(1):1-8

7. Tomaszewski M, Topyła W, Kijewski BG, Miotła P, Waciński P. Does gender influence the outcome of ischemic heart disease? Przeglad menopauzalny. 2019; 18(1):11-56.

8. Díez-Villanueva P, Alfonso F. Heart failure in the elderly. J Geriatr Cardiol. 2016; 13(2):115-7.

9. Lazzarini V, Mentz RJ, Fiuzat M, Metra M, O'Connor CM. Heart failure in elderly patients: distinctive features and unresolved issues. Eur J Heart Fail. 2013;15(7):717-23.

10. Chioncel O, Mebazaa A, Maggioni AP, Harjola VP, Rosano G, Laroche C. et al. Acute heart failure congestion and perfusion status-impact of the clinical classification on in-hospital and longterm outcomes; insights from the ESC-EORP-HFA Heart Failure LongTerm Registry. Eur J Heart Fail. 2019; 21(11):1338-52.

11. Kurmani S, Squire I. Acute heart failure: definition, classification and epidemio logy. Current Heart Failure Reports. 2017;14(5):385-92.

12. Upadhya B, Rocco M, Lewis CE, Oparil S, Lovato LC, Cushman WC, et al. Circ Heart Fail. 2017;10(4):1-10.

13. Hypertension [Internet]. [cited 2019 Dec 9]. Available from: www.who.int/news room/factsheets/detail/hypertension

14. Menggasa ER, Kaunang WP, Kalesaran AF. Hubungan antara obesitas dengan kejadian hipertensi pada pasien rawat jalan di Puskesmas Ranomut Kota Manado. Kesmas. 2019;7(5).

15. Tesfaye B, Haile D, Lake B, Belachew T, Tesfaye T, Abera H. Uncontrolled hypertension and associated factors among adult hypertensive patients on follow-up at Jimma University Teaching and Specialized Hospital: cross-sectional study. Research Reports in Clinical Cardiology. 2017;8:21.

16. Nadruz Jr W, West E, Santos M, Skali H, Groarke JD, Forman DE, et al. Heart failure and midrange ejection fraction: implications of recovered ejection 
fraction for exercise tolerance and outcomes. Circ Heart Fail. 2016;9(4):18.

17. Understand your risks to prevent a heart attack [Internet]. [cited 2019 Sep 9]. Available from: www.heart.org.

18. Garfinkel AC, Seidman JG, Seidman CE. Genetic pathogenesis of hypertrophic and dilated cardiomyopathy. Heart Failure Clinics. 2018;14(2):139-46.

19. Shahid F, Lip GY. Atrial fibrillation and heart failure: how should we manage our patients? Arrhythmia \& Electrophysiology Review. 2016;5(3): 162-3.

20. Kotecha D, Piccini JP. Atrial fibrillation in heart failure: what should we do? Eur Heart J. 2015; 36(46):3250-7.

21. Jaulent HL, Consuegra SL, Vicente GM, Melgarejo MA, Alonso FN, Díaz PA, et al. Prognostic importance of cardiomegaly in patients with acute myocardial infarction. Emergencias: revista de la Sociedad Espanola de Medicina de Emergencias. 2015;27(5):294-300.

22. Amin H, Siddiqui WJ. Cardiomegaly. InStatPearls [Internet] 2019 Jun 4. StatPearls Publishing.
23. Lee JH, Kim MS, Kim EJ, Park DG, Cho HJ, Yoo BS, Kang SM, Choi DJ. KSHF guidelines for the management of acute heart failure: part I. definition, epidemiology and diagnosis of acute heart failure. Korean Circulation Journal. 2019;49(1):1-21.

24. Kumar V, Abbas AK, Aster JC. Robbins and Cotran Pathologic Basis of Disease (9th ed). Philadelphia, PA: Saunders, 2014; p. 523-78.

25. Palazzuoli A, Ruocco G, Ronco C, McCullough PA. Loop diuretics in acute heart failure: beyond the decongestive relief for the kidney. Critical Care. 2015;19(1):296.

26. Michael F, John RT. Braunwald's Heart Disease. A Textbook of Cardiovascular Medicine (11th ed). Elsevier: 2019; p. 462-89.

27. Ryder M, Murphy NF, McCaffrey D, O'Loughlin C, Ledwidge M, McDonald K. Outpatient intravenous diuretic therapy; potential for marked reduction in hospitalisations for acute decompensated heart failure. Eur J Heart Fail. 2008;10(3):267-72. 